Bond University

Research Repository

\title{
An efficient and robust HPLC method to determine the sialylation levels of human epithelial cells
}

Kim, Hyo Jeong; Schweiker, Stephanie; Powell, Katie; Levonis, Stephan

Published in:

PLoS One

DOI:

10.1371/journal.pone.0257178

Licence:

CC BY

Link to output in Bond University research repository.

Recommended citation(APA):

Kim, H. J., Schweiker, S., Powell, K., \& Levonis, S. (2022). An efficient and robust HPLC method to determine the sialylation levels of human epithelial cells. PLoS One, 17(1), [e0257178].

https://doi.org/10.1371/journal.pone.0257178

\section{General rights}

Copyright and moral rights for the publications made accessible in the public portal are retained by the authors and/or other copyright owners and it is a condition of accessing publications that users recognise and abide by the legal requirements associated with these rights.

For more information, or if you believe that this document breaches copyright, please contact the Bond University research repository coordinator. 


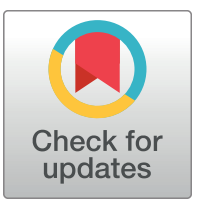

\section{G OPEN ACCESS}

Citation: Kim HJ, Schweiker S, Powell K, Levonis S (2022) An efficient and robust HPLC method to determine the sialylation levels of human epithelial cells. PLoS ONE 17(1): e0257178. https://doi.org/ 10.1371/journal.pone.0257178

Editor: A. M. Abd El-Aty, Cairo University, EGYPT

Received: August 19, 2021

Accepted: December 16, 2021

Published: January 18, 2022

Copyright: @ $2022 \mathrm{Kim}$ et al. This is an open access article distributed under the terms of the Creative Commons Attribution License, which permits unrestricted use, distribution, and reproduction in any medium, provided the original author and source are credited.

Data Availability Statement: All relevant data are within the manuscript and its Supporting information files.

Funding: This research was made possible by the Australian Rotary Health/Rotary Club of Sandy Bay 'Michael Chivers' PhD scholarship. The recipient of the award was author H. Kim. A grant number is not applicable. The funders had no role in study design, data collection and analysis, decision to publish, or preparation of the manuscript.

Competing interests: The authors have declared that no competing interests exist.
RESEARCH ARTICLE

\section{An efficient and robust HPLC method to determine the sialylation levels of human epithelial cells}

\author{
Hyo Jeong Kim $^{\circledR}$, Stephanie Schweiker ${ }^{\odot}$, Katie Powell ${ }^{\circledR}$, Stephan Levonis $\mathbb{D}^{*}$ \\ Faculty of Health Sciences and Medicine, Bond University, Gold Coast, Queensland, Australia \\ ๑ These authors contributed equally to this work. \\ * slevonis@ bond.edu.au
}

\section{Abstract}

Sialyltransferase, an enzyme responsible for attaching sialic acid to the cell surface, is reported to play a key role in cancer, making sialyltransferase a potential therapeutic target in drug development. Several methods have been developed to quantify sialic acids in biological samples however limitations exists and quantification in complex cell matrices lack investigation. Hence, this paper outlines a simple method to detect and quantify sialic acids in cancer cells for evaluating sialyltransferase activity of potential therapeutic compounds. An efficient method was developed using a reverse-phase ion-pairing HPLC-UV using triisopropanolamine as the ion-pairing agent with a $\mathrm{C} 18$ column. Neu5Ac was successfully eluted with the retention time $6.344 \mathrm{~min}$ with a flow rate of $0.4 \mathrm{~mL} / \mathrm{min}$. The proposed method was validated appropriately according to the AOAC guidelines (2013). This work demonstrates that the proposed method is not only relatively simple but also cost and time effective compared to pre-existing methods to successfully determine both free and protein-bound Neu5Ac in a complex cancer cell matrix. Furthermore, by applying the proposed method, a statistically significant decrease was observed for both HeLa and HuCCT1 cell lines with the application of deoxycholic acid-a known sialyltransferase inhibitor. Hence, the proposed method seems promisingly applicable to evaluate the effectiveness of potential sialyltransferase inhibitors.

\section{Introduction}

Sialic acid (Sia) is a generic term for nitrogen or oxygen substituted derivatives of neuraminic acid-a nine-carbon monosaccharide [1]. They appear as either free or bound to protein in nature and are widely expressed as the outer terminal units of glycans on the surfaces of all vertebrate cells $[2,3]$. $\mathrm{N}$-acetylneuraminic acid (Neu5Ac) is the most predominant type of sia on mammalian cells, synthesised via various biological pathways in human [1]. In this paper, "sialic acid" refers to Neu5Ac unless specifically emphasized. Due to their unique location and abundance on the cell surface, sias participate in a wide variety of human pathophysiological processes, including cell-to-cell adhesion, tumour cell metastasis, and in the process of 
inflammation [4-7]. In addition to the key roles mentioned above, sias are known to "sweeten" the life of tumour cells by aberrant sialylation [8]. Hypersialylation is common in cancer cells where it assists in inhibiting the apoptosis signals and building resistance towards cancer therapy $[8,9]$. Sialyltransferases are the enzymes responsible for attaching sialic acid to the cell membrane [9]. Hence, sialyltransferase inhibitors have been investigated as a potential therapeutic target in drug development for cancer [7, 9]. By quantifying the sias in cancer cells as an attempt to evaluate the effectiveness of sialyltransferase inhibitors, further development may be enabled to ultimately provide a promising new strategy to treat cancer without, disturbing physiologically important sialylation.

Various methods and techniques ranging from colorimetry, fluorometric to enzymatic and chromatographic analysis have been reported to determine sias $[3,10]$. The Warren thiobarbituric acid method (1959) is the prominent spectrophotometric approach to determine sias [10]. However, this method is known to lack sensitivity. Thin Layer Chromatography is another popular approach to separate and quantify sias but it consists of complex procedures [11].

Furthermore, when quantifying sias in complex cancer matrix, existing approaches hold limitations of requiring entire tissue samples to extract, lack classification amongst diverse cell types, and overlook major glycans on minor cell types [12]. Under normal circumstances, sias are typically found as part of a glycoconjugate (approximately 73\%) rather than as a free acid [2]. Thus, for accurate analysis, sias need to be purified and completely released from the respective glycoproteins, glycolipids and oligosaccharides prior to the analysis.

An acid hydrolysis method is a popular approach to determine sias as it releases sias without causing significant changes in their modification from the biological sources [3]. Several published studies have used sulfuric acid to release sias but other acids such as acetic acid, trifluoroacetic acid and hydrochloric acid, are also commonly used for their availability, cost, and most importantly for their volatility; they are easily removable by lyophilization [13, 14]. Following acid hydrolysis, numerous spectroscopic approaches exist to determine sias. These approaches hold a major limitation of overestimating the concentration of sias via interferences [15]. Therefore, when developing a chromatographic method, there is a substantial focus on separating sias from the interfering compounds. One proven approach that is sensitive, specific and applicable to most sias is via derivatization with 1,2-diamino-4,5-methylenedioxybenzene dihydrochloride (DMB) followed by high-performance liquid chromatography (HPLC) analysis with fluorescence detection [16]. However, despite an improvement in the chromatographic separation via DMB-labeled sias, the derivatization methods require reagents that are costly and often not time efficient.

Hence, despite advancements, there are limitations currently associated with determining sias in a complex matrix, such as in cancerous cells. This research will outline a reverse-phase ion pair HPLC method for exploring these limitations via simple precipitation of sias with ethanol followed by acid hydrolysis to isolate the sias bound to protein. The method will then be evaluated by measuring changes in sia level in various cancerous cell lines with and without known sialyltransferase inhibitor.

\section{Materials and methods}

\section{Chemicals, reagents, and materials}

The reagents: Triisopropanolamine (TIP), phosphoric acid, hydrochloric acid (HCl), sodium hydroxide $(\mathrm{NaOH})$, and ethanol (HPLC grade) were purchased from Sigma-Aldrich (Australia). Neu5Ac standard (HPLC grade, $\geq 97 \%$ ) was also purchased from Sigma-Aldrich (Australia). Filter paper $(0.45 \mu \mathrm{m}, 25 \mathrm{~mm}$ Diameter Hydrophobic PTFE) was manufactured from 
Aijiren Corp (Quzhou, China). All standard solutions and the mobile phase (TIP solution) were prepared with deionized water obtained from Milli-Q water system (Millipore S.A.S 67120 Molsheim France).

Cell culture reagents, Fetal Bovine Serum (FBS), Dulbecco's Modified Eagle Medium (DMEM), Streptomycin/Penicillin and TrypLE were purchased from Gibco by life technologies (Denmark). Pre-made Phosphate buffer solution (PBS) at appropriate concentrations and $\mathrm{pH}$ was purchased from Sigma-Aldrich (Australia).

\section{Instrumentation}

An electronic $\mathrm{pH}$ probe was used for creating the buffered TIP solution accordingly. Calibrated automatic pipettes and analytical balance were used for the volume and weight measurement. The mass of the cells was measured by a XSE105 Dual Range Mettler Toledo weighing balance.

The samples were detected and quantified via a reverse phase HPLC. All HPLC analyses were performed on a HPLC Waters Alliance e2695 Separation Module (Waters Corporation, Milford, MA, USA) coupled to a Waters 2489 UV/Visible Detector set at $215 \mathrm{~nm}$. The separation was performed on the $\mathrm{C}_{18}$ column Luna $5 \mu \mathrm{m}$ (2) $100 \mathrm{~A} 250$ x $4.5 \mathrm{~mm}$ (Phenomenex Inc., Torrance, CA, USA).

\section{Chromatographic condition of HPLC}

All separations were performed isocratically at $25^{\circ} \mathrm{C}$ with a mobile phase comprised of $50 \mathrm{mM}$ TIP solution buffered to $\mathrm{pH} 3.5$ via phosphoric acid (99\% Sigma-Aldrich, Australia). The flow rate was maintained at $0.4 \mathrm{~mL} / \mathrm{min}$. A $10 \mu \mathrm{L}$ sample volume was injected directly for all experiments with two repeated injection of a $10 \mu \mathrm{L}$ blank TIP buffer solutions between each sample runs to reduce possible interference peaks. The sias eluted from the column were monitored by a UV/VIS spectrophotometer set at $215 \mathrm{~nm}$. Peak identification was performed by comparing the retention times and absorption spectra of the respective standard solutions with the prepared samples.

\section{Preparation of standard and stock solution}

The standard stock solution of Neu5Ac $(1.0 \mathrm{mM})$ was prepared by the addition of $3.1 \mathrm{mg}$ of Neu5Ac in a $10 \mathrm{~mL}$ flask. TIP buffer solution $(50 \mathrm{mM})$ was added to reach a final volume of 10 $\mathrm{mL}$ and stored at $4^{\circ} \mathrm{C}$ in a fridge. The working standard solutions were produced by diluting the respective stock solution in $50 \mathrm{mM}$ TIP buffer solution to form $0.03125,0.0625,0.125$, $0.25,0.50$ and $1.0 \mathrm{mM}$. The working standard solutions were freshly prepared before the start of the analysis via serial dilution using the stock solution.

\section{Sample collection and preparations}

Culturing conditions for the cells. Total of two carcinoma cell lines: human epithelial cervical adenocarcinoma (HeLa; American Type Culture Collection) and the human liver bile duct carcinoma (HuCCT1; Cellbank Australia) were used for the experiment. The HeLa cell line was supplied by the ATCC (Manassas, USA) as catalogue number ATCC ${ }^{\circledR}$ CCL2 $2^{\mathrm{m}}$, and was purchased from In Vitro Technologies (Noble Park North, VIC, Australia). The HeLa cell line has been described before [17]. The HuCCT1 cell line was supplied by the JCRB Cell Bank (Osaka, Japan) as catalogue number JCRB0425, and was purchased from CellBank Australia (Westmead, NSW, Australia). The HuCCT1 cell line has been described before [18]. 
The culturing conditions for both HeLa and HuCCT1 cell lines were optimised. The cells were cultured in DMEM supplemented with 10\% FBS and 0.1\% Streptomycin/Penicillin in T-75 flask. The cells were maintained at $37^{\circ} \mathrm{C}$ in a humidified atmosphere of $5 \%$ carbon dioxide. Cells were prepared at 90 to $100 \%$ confluency. Once cells had reached confluency, cells were incubated for 15 minutes with TrypLE to be detached from the flask. Cells were washed with PBS solution and centrifuged prior to the sample preparation. The cells were kept in a freezer at negative $80^{\circ} \mathrm{C}$ until analysis. Cells were thawed to room temperature $\left(25^{\circ} \mathrm{C}\right)$ prior to the analysis.

\section{Cell preparations}

Free sialic acids. Prior to the sample preparation step, the cultured cells were washed with $1 \mathrm{~mL}$ of phosphate-buffered saline (PBS) solution in attempt to remove residual growth medium. Ethanol $(2 \mathrm{~mL})$ was added to the washed samples to precipitate free sias. The solution was inverted ( 4 times), vortexed $(1 \mathrm{~min})$ and rested at room temperature $\left(25^{\circ} \mathrm{C}\right)$ for $10 \mathrm{~min}$ utes. It was then centrifuged $\left(150 \mathrm{~g}, 25^{\circ} \mathrm{C}\right)$ for 5 minutes. The supernatant containing the free sias was dried completely using a rotary evaporator under high vacuum to eliminate ethanol contamination. The mass of the cells was obtained by measuring the vacuum reduced supernatant. The $0.3 \mathrm{~mL}$ of TIP buffer solution was added to the reduced supernatant. The solution was filtered before HPLC analysis.

Protein-bound sialic acids. The remaining pellet from the first centrifuge was hydrolysed to release protein-bound sias. The pellet was crushed and mixed with $1 \mathrm{~mL}$ of $\mathrm{HCl}(120 \mathrm{mM})$. It was heated for an hour at $80^{\circ} \mathrm{C}$. After the hydrolysis step, the solution was neutralized to a $\mathrm{pH}$ of 7.0 with $1 \mathrm{~mL}$ of $\mathrm{NaOH}(120 \mathrm{mM})$. Ethanol $(4 \mathrm{~mL})$ was added to the mixture before it was inverted (4 times), vortexed $(1 \mathrm{~min})$ and rested at room temperature $\left(25^{\circ} \mathrm{C}\right)$ for 10 minutes. The hydrolysed solution was centrifuged $\left(150 \mathrm{~g}, 25^{\circ} \mathrm{C}\right)$ for 5 minutes. The supernatant was reduced completely using a rotary evaporator under high vacuum to remove ethanol. Mass of the cell was measured. The $0.3 \mathrm{~mL}$ of TIP buffer solution was added to the vacuum reduced supernatant prior to the HPLC analysis. The solution was filtered before HPLC analysis.

\section{Method validation}

The performance of the HPLC-UV method to determine sias in cultured cells was validated in terms of linearity, selectivity, accuracy (recovery), repeatability precision, Limit of Detection (LOD) and Limit of Quantification (LOQ) according to the 2013 Association of Official Analytical Chemists (AOAC) international guideline.

Linearity. Linearity was calculated by three injections of different Neu5Ac concentrations $(0.03125,0.0625,0.125,0.25,0.50$ and $1.0 \mathrm{mM})$ where the average peak areas were plotted against concentrations. Coefficient of correlation $\left(\mathrm{R}^{2}\right)$ obtained from the respective calibration curve was used to evaluate the linearity. According to the AOAC guideline, the acceptable value for $\mathrm{R}^{2}$ is greater than 0.998 .

Selectivity. Selectivity was determined by examining the chromatograms to verify the absence of interfering peaks in the prepared samples.

Accuracy (recovery). The accuracy of the method was evaluated by the percent recovery (R\%) of the spiked analyte. The standard stock solution $(0.50 \mathrm{mM})$ was spiked $(10,20,30,40$ and $50 \mu \mathrm{L}$ ) five times individually into the three prepared samples with low, medium and high concentration of sias. The spiked samples were injected in triplicate.

The percent recovery of the analyte was calculated using the formula:

$$
R \%=\frac{C_{f}-C_{u}}{C_{a}} \times 100 \%
$$


where $C_{f}$ represents the amount of sias quantified after the addition of the standard stock solution, $C_{u}$ represents the amount of sias quantified prior to spiking and $C_{a}$ refers to the amount of standard stock solution added. Acceptable recovery according to the guidelines is within 80 to $120 \%$ of the mean.

Precision. Precision was evaluated by intra-day and inter-day testings. For repeatability precision (intra-day), three replicates of the quality control samples containing all the analytes at three different concentrations (low, medium and high) were analysed simultaneously at six different times on the same day. For intermediate precision (inter-day), the analysis was performed over three successive days.

Precision was expressed as the relative standard derivation (RSD\%) and was calculated using the formula:

$$
R S D \%=\frac{S D}{\bar{x}} \times 100 \%
$$

where $S D$ represents the standard deviation and $\bar{x}$ refers to the sample mean. RSD\% value less than or equal to $2 \%$ was accepted according to the guidelines.

Limit of detection and limit of quantification. The LOD and LOQ was calculated using the formula:

$$
L O D=\frac{3 \times S D_{y}}{m_{s}}, \quad L O Q=\frac{10 \times S D_{y}}{m_{s}}
$$

where $S D_{y}$ represents the standard deviation of the y-intercepts and $m_{s}$ refers to the average gradients from respective standard calibration curve.

\section{Statistical analysis}

Repeated Measures Analysis of Variance (RM ANOVA) was used to statistically compare the difference in sia level in cultured cells with/without the addition of known sialyltransferase inhibitors-deoxycholic acid. The sia levels from the control group (no addition of sialyltransferase inhibitor) were individually compared to the other conditions with varying concentration of deoxycholic acid. All statistical calculations were performed using the Statistical Package for the Social Sciences (SPSS) program. P value lower than 0.05 would indicate that the sia level in the comparison cells with a sialyltransferase inhibitor applied are statistically different from the control group.

\section{Results}

\section{HPLC method development and optimisation}

Method validation. As summarised in Table 1 , the developed method was validated as per the criteria set by the AOAC international guideline (2013).

Linearity. The linearity of the method was examined by the calibration curve plotted between the area of the respective peaks against the five standard concentrations of Neu5Ac over the range of 0.03125 to $1 \mathrm{mM}$ (Fig 1 ).

The average $R^{2}$ was determined to be 0.9998 for Neu5Ac (Table 1). Thus, as the $R^{2}$ for individual analytes was achieved to be $>0.998$, the proposed method is linear and acceptable as it satisfies the AOAC guideline.

Selectivity. The proposed method was proven to have selectivity due to absence of significant interference peaks at the retention times of the Neu5Ac (Fig 2). Furthermore, by blanking 
Table 1. Summary of the correlation coefficient, accuracy, precision, LOD and LOQ values for the proposed method.

\begin{tabular}{l|c}
\hline & Neu5Ac \\
\hline Co-efficient of Determination $\left(\mathbf{R}^{\mathbf{2}} \pm \mathbf{S D}\right)$ & 0.9999 \\
\hline Average accuracy $(\mathbf{R} \% \mathbf{n}=\mathbf{5})$ & $116 \%$ \\
\hline Average inter-day precision $(\mathbf{R S D} \%, \mathbf{n}=\mathbf{3})$ & $1.99 \%$ \\
\hline Average intra-day precision $(\mathbf{R S D} \%, \mathbf{n}=\mathbf{3})$ & $0.85 \%$ \\
\hline LOD $(\mathbf{m M})$ & 0.002487 \\
\hline LOQ $(\mathbf{m M})$ & 0.007537 \\
\hline
\end{tabular}

https://doi.org/10.1371/journal.pone.0257178.t001

with TIP solutions twice for each sample run, no carry-over effect was observed throughout the analysis.

Accuracy (recovery). The average recovery for high concentration of Neu5Ac sample was found to be $109 \%$. All recovery values obtained (Table 2) were within the range 80 to $120 \%$, indicating high accuracy of the proposed method.

Precision. As summarised on Table 3, the proposed method has acceptable precision, including repeatability and intermediate precision, as all RSD\% values were less than $2 \%$.

LOD and LOQ. The LOD and LOQ determined for Neu5Ac were $0.002487 \mathrm{mM}$, $0.007537 \mathrm{mM}$ respectively. The low LOD and LOQ of Neu5Ac enables the detection and quantification of Neu5Ac in cultured cells at low concentrations.

\section{Application}

By measuring sia levels in cancer cells, the effectiveness of potential inhibitors for hypersialylation can be evaluated. Hence, the developed method was applied to compare the difference in the sia level in untreated cultured malignant cells against the cultured malignant cells treated with the known sialyltransferase inhibitor-deoxycholic acid, for 48 hours. The HeLa and HuCCT1 cell lines were used for the application.

To determine the cytotoxicity of deoxycholic acid, malignant cells with various concentration of known sialyltransferase inhibitors (ranging from 3 to $300 \mu \mathrm{M}$ ) were dissolved in culture media and cultured for 48 hours. Preliminary qualitative results were taken by a light microscope, followed by a quantitative measure via a high sensitivity flow cytometer (BD FACSAria ${ }^{\text {me }}$

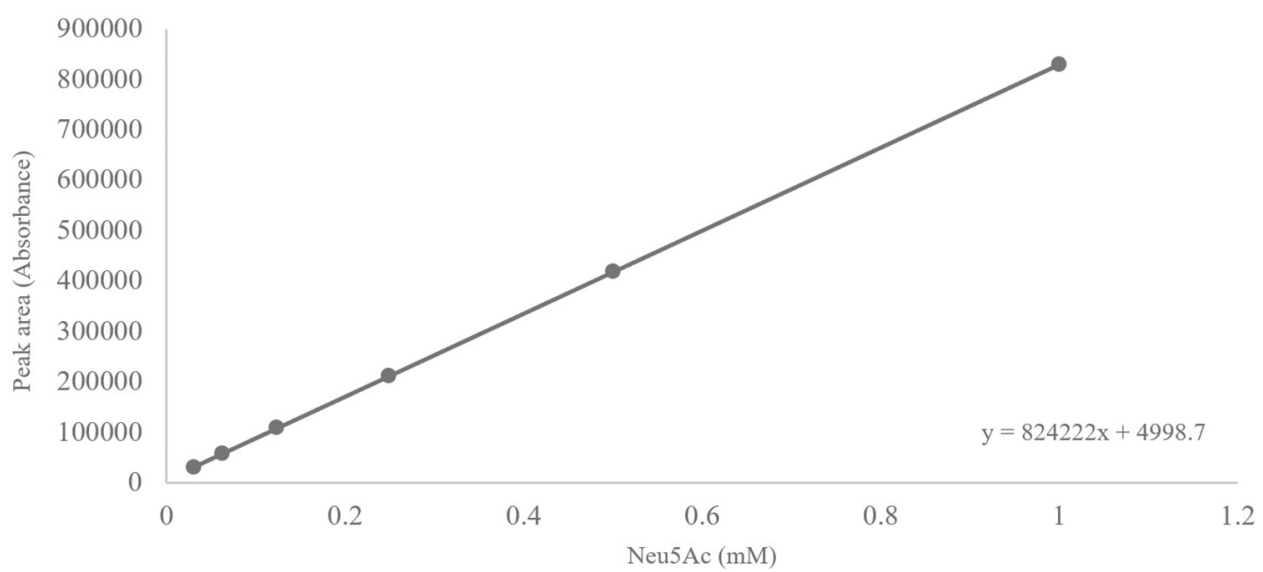

Fig 1. Calibration curve showing the linearity of the method: Neu5Ac.

https://doi.org/10.1371/journal.pone.0257178.g001 


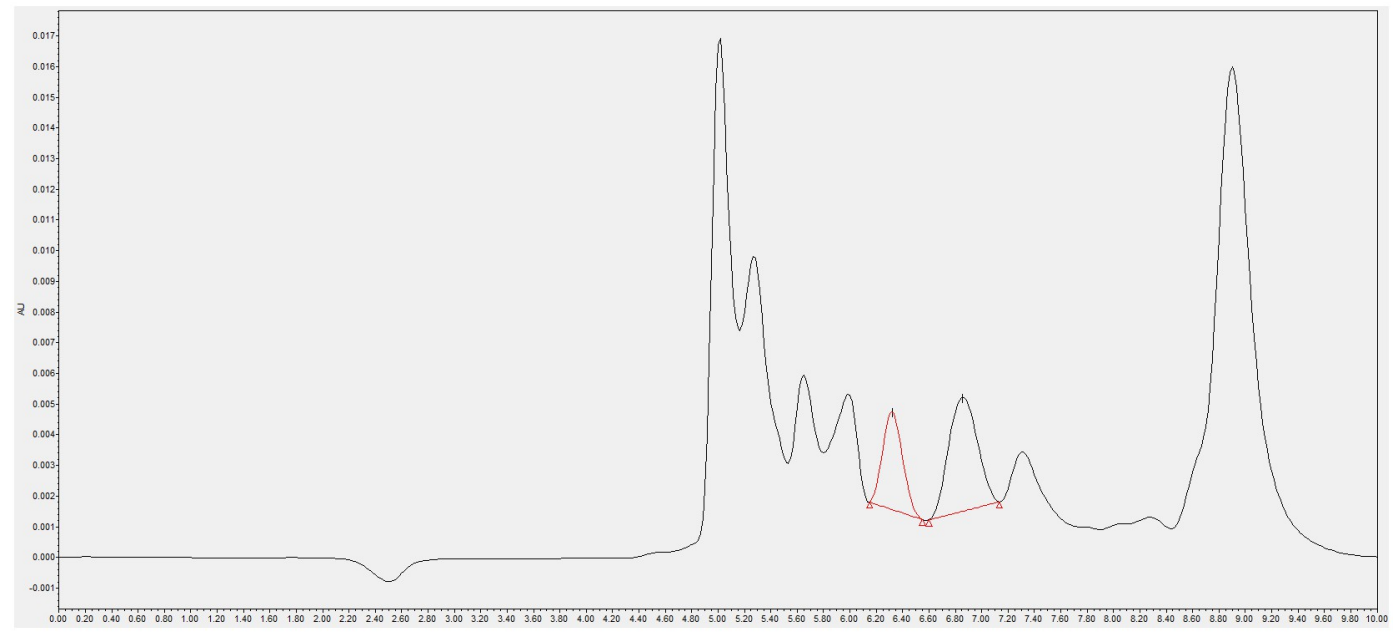

Fig 2. A chromatogram of cultured HeLa cells via using the optimised HPLC method. Absence of significant interference peaks at the retention times ( 6.344 minutes with a flow rate of $0.4 \mathrm{~mL} / \mathrm{min}$.) of Neu5Ac has been highlighted in red.

https://doi.org/10.1371/journal.pone.0257178.g002

III) for live/dead cell discrimination. No significant changes in cell viability were observed for cells treated with less or equal to $150 \mu \mathrm{M}$ of deoxycholic acids

As depicted in Fig 3, a general decrease in the total sia level was observed as the amount of deoxycholic acid increased for both HeLa and HuCCT1 cells. The average total sia level for HeLa cells were $0.0062 \mathrm{mM} / \mathrm{mg}$ of protein $(0 \mu \mathrm{M}), 0.0037 \mathrm{mM} / \mathrm{mg}$ of protein $(75 \mu \mathrm{M})$ and $0.0027 \mathrm{mM} / \mathrm{mg}$ of protein $(150 \mu \mathrm{M})$. The average total sia level for HuCCT1 cells were 0.0046 $\mathrm{mM} / \mathrm{mg}$ of protein $(0 \mu \mathrm{M}), 0.0027 \mathrm{mM} / \mathrm{mg}$ of protein $(75 \mu \mathrm{M})$ and $0.0024 \mathrm{mM} / \mathrm{mg}$ of protein $(150 \mu \mathrm{M})$. A repeated measure ANOVA determined that the mean sia level for both HeLa $(\mathrm{F}=31.110 \mathrm{p}<0.0005)$ and HuCCT1 $(\mathrm{F}=16.787, \mathrm{p}<0.005)$ cell line differed statistically significantly as the deoxycholic acid concentration increased. Therefore, as represented in Fig 3 , it is concluded that the average amount of sia decreased for $75 \mu \mathrm{M}$ and $150 \mu \mathrm{M}$ trials were statistically significantly different to the control group $(\mathrm{p}<0.05)$.

Fig 3 suggests that as the level of deoxycholic acid increases, the level of sia decreases. This trend suggests that deoxycholic acid, a known lithocholic analogue sialyltransferase inhibitor, has successfully inhibited sialylation in both HeLa and HuCCT1 cells where higher concentration of deoxycholic acid was linked with the extent of sialylation. Therefore, the proposed HPLC method seems to reliably measure the extent of sialylation where it could be used to evaluate potential sialyltransferase inhibitors.

Table 2. Results for accuracy $(n=3)$ for the proposed method to determine Neu5Ac level.

\begin{tabular}{c|c|c|c}
\hline $\begin{array}{c}\text { Neu5Ac Spiked Amount } \\
(\mathbf{m M})\end{array}$ & $\begin{array}{c}\text { Volume of Neu5Ac } \\
(\boldsymbol{\mu} \mathbf{L})\end{array}$ & $\begin{array}{c}\text { Volume of sample } \\
(\boldsymbol{\mu} \mathbf{L})\end{array}$ & $\begin{array}{c}\text { Average Neu5Ac Recovery }(\%, \\
\mathbf{n}=\mathbf{3})\end{array}$ \\
\hline- & - & 300 & - \\
\hline 0.5 & 10 & 290 & $99.6 \%$ \\
\hline 0.5 & 20 & 280 & $108.0 \%$ \\
\hline 0.5 & 30 & 270 & $109.9 \%$ \\
\hline 0.5 & 40 & 260 & $110.2 \%$ \\
\hline 0.5 & 50 & 250 & $117.3 \%$ \\
\hline
\end{tabular}

https://doi.org/10.1371/journal.pone.0257178.t002 
Table 3. Results of precision for the proposed method to determine Neu5Ac level.

\begin{tabular}{c|c|c|c|c|c|c}
\hline \multirow{2}{*}{ Concentration } & \multicolumn{3}{|c|}{ Repeatability (Intra-day) } & \multicolumn{3}{c}{ Intermediate precision (Inter-day) } \\
\cline { 2 - 6 } & Mean (mM) & SD & RSD\% & Mean (mM) & SD & 0.00000 \\
\hline Low & 0.0234 & 0.00054 & $1.34 \%$ & 0.001 & $0.00 \%$ \\
\hline Medium & 0.1448 & 0.00238 & $1.65 \%$ & 0.236 & 0.00400 \\
\hline High & 0.4313 & 0.00857 & $1.99 \%$ & 0.603 & 0.00513 & $0.85 \%$ \\
\hline
\end{tabular}

https://doi.org/10.1371/journal.pone.0257178.t003

\section{Discussion}

The sias in cancer cells were detected and quantified via a reverse phase HPLC with TIP buffer solution as the ion-pairing reagent. The method was inspired from the novel study by Spyridaki and Siskos in 1999 and optimised to suit our needs for this purpose. Parameters such as chromatography conditions, mobile phase, hydrolysis conditions and sample amounts were modified to improve the analytical performance. The optimized method resulted in successful separation where Neu5Ac was eluted with a retention time of 6.344 minutes with a flow rate of $0.4 \mathrm{~mL} / \mathrm{min}$.

When analyzing complex matrices like cancer cells, several issues may be of concern. Samples derived from metabolically engineered cells may contain variable concentration of sias depending on cell passage number, splitting condition or cell confluency. Nevertheless, by having control cell for each trial, a statistical approach can still be taken by comparing the sias concentration as a relative percentage of given control per trial.

The proposed method also assumes all types of sias are free or protein-bound sias. The outlined method cannot differentiate different types of sias such as Neu5Ac and CMP-Neu5Ac. However, this method is still able to act as a rapid and highly effective screening tool to evaluate the extent of sialylation of proposed inhibitors.

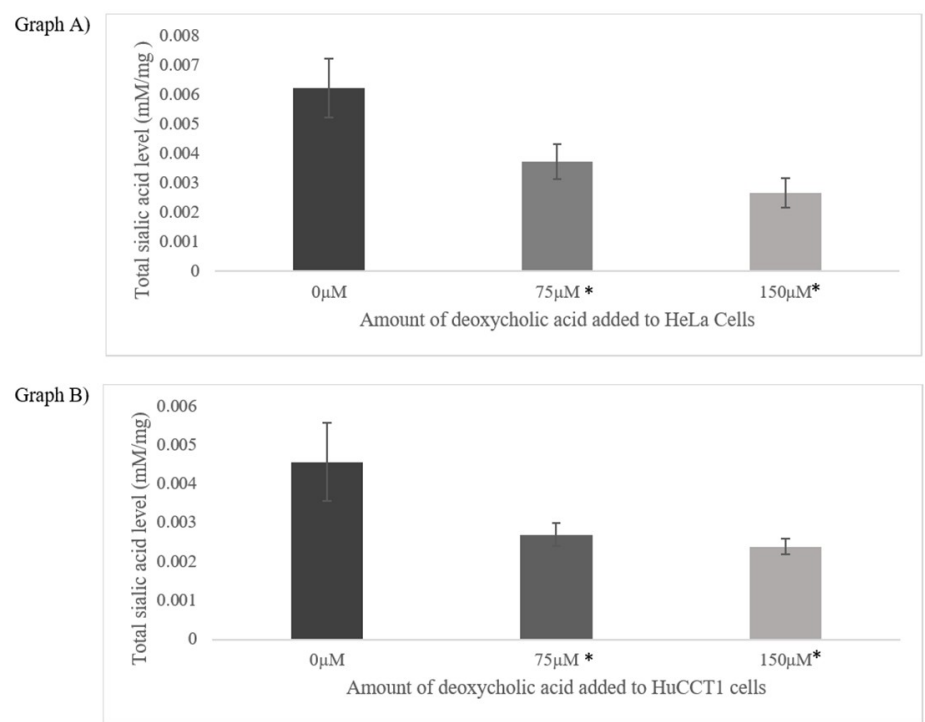

Fig 3. The changes in the total sialic acid level according to various concentration of deoxycholic acid $(0 \mu \mathrm{M}$, $75 \mu \mathrm{M}$ and $150 \mu \mathrm{M})$ added for HeLa (Graph A) and HuCCT1 (Graph B) cells. The values are mean \pm SD, $n=6$. The asterisks indicate the total sialic acid level for $75 \mu \mathrm{M}$ and $150 \mu \mathrm{M}$ were statistically significantly different to the control Neu5Ac level: ${ }^{*} \mathrm{P}<0.05$.

https://doi.org/10.1371/journal.pone.0257178.g003 
Any matrix effect was attempted to be evaluated in this study. However, since cell sample without the presence of Neu5Ac are not available, analyte suppression by interfering substances was investigated by the average recovery. As mentioned in Table 2, the cell samples were spiked with five known concentrations of the standard Neu5Ac, resulting in 109\% as the average recovery. Furthermore, as the proposed method primarily aimed to be used as a method to evaluate the extent of sialylation, and not as a method to quantify the sialic acid as a biomarker, any matrix effect would be classified as systematic error.

To date, derivatization with DMB together with the HPLC analysis is the popular approach to detect sias in biological samples [10]. Many studies were already able to sensitively quantify sias in various biological samples including human urine and blood. However, there are limited number of studies that attempt to quantify sias in cancer cell lines. Furthermore, amongst the limited cancer cell studies to this date, no method has been reported that does not require a derivatization process for HPLC analysis.

The proposed method was optimized to remove any form of derivatization process, allowing required reagents to be inexpensive and easily accessible like ethanol and hydrochloric acid. Furthermore, the simplicity of the proposed method allows the whole procedure including the sample preparation, analysis, and calculation of results to be performed in 2 hours. A short procedure is advantageous, especially when the proposed method is aimed to be used as a high throughput screen for early stage sialyltransferase inhibitor development.

Research groups have attempted to quantify sias in human serum to use as a biomarker for Salla disease (sialic acid storage disease) by LC-MS/MS [12, 19, 20]. Similarly, to the proposed method, no derivatization is required with relatively short procedure (2-4 h). LC-MS/MS may provide more sensitivity than HPLC-UV, however the mobile phase must be volatile and the sample must be specifically prepared prior to the analysis. In addition, any samples are destroyed during the analysis due to the process of mass spectrometry. Hence, HPLC-UV may be a more appropriate technology to be used to investigate complex cancer cell matrix. Furthermore, as the proposed method aimed to compare sialylation between cancer cells with and without sialyltransferase inhibitors, a less sensitive approach is allowed as the sias level quantified will not be analyzed as a biomarker.

Hence, the proposed method, as appropriately validated according to the AOAC guideline, is relatively sensitive but very simple in terms of costs and time in comparison to any existing methods. It could act as the suitable method to rapidly screen potential sialyltransferase inhibitors and may contribute greatly towards early-stage drug development.

\section{Conclusion}

This research aimed to develop a simple method to detect and quantify sias in cancer cells. This method may find a use in evaluating the effectiveness of potential sialyltransferase inhibitors. Sias were released and purified through an isolation technique with ethanol precipitation and acid hydrolysis. The samples were then detected and quantified via reverse phase HPLC with TIP buffer solution as the ion-pairing reagent. The proposed method resulted in Neu5Ac eluted with the retention time of 6.344 minutes with a flow rate of $0.4 \mathrm{~mL} / \mathrm{min}$. The proposed method was validated appropriately according to the AOAC guidelines (2013). This work demonstrates that the proposed method is not only relatively simple but also low-cost and time efficient compared to pre-existing methods to successfully determine both free and protein-bound Neu5Ac in a complex cancer cell matrix. The proposed method seems to be applicable in reliably measuring the extent of sialylation in malignant cells to evaluate the effectiveness of potential sialyltransferase inhibitors. The proposed method may allow rapid 
and convenient way to explore the sialylation of carcinoma cells and provide positive insight into drug development for cancer treatment.

\section{Supporting information}

S1 File. Summary statistics including all the raw data. (XLSX)

\section{Author Contributions}

Conceptualization: Hyo Jeong Kim, Stephanie Schweiker, Stephan Levonis.

Formal analysis: Hyo Jeong Kim, Stephan Levonis.

Investigation: Hyo Jeong Kim.

Methodology: Hyo Jeong Kim, Katie Powell.

Project administration: Stephanie Schweiker, Stephan Levonis.

Resources: Katie Powell.

Supervision: Katie Powell, Stephan Levonis.

Writing - original draft: Hyo Jeong Kim, Stephan Levonis.

Writing - review \& editing: Hyo Jeong Kim, Stephanie Schweiker, Stephan Levonis.

\section{References}

1. Tiralongo J., \& Martinez-Duncker I. (2013). Sialobiology. Sharjah, U.A.E.: Bentham Science Publishers.

2. Wang B., \& Brand-Miller J. (2003). The role and potential of sialic acid in human nutrition. European Journal Of Clinical Nutrition, 57(11), 1351-1369. https://doi.org/10.1038/sj.ejcn.1601704 PMID: 14576748

3. Varki A., Cummings R., \& Esko J. (2009). Essentials of Glycobiology (2nd ed.). New York: Cold Spring Harbor Laboratory Press.

4. Grivennikov S., Greten F., \& Karin M. (2010). Immunity, Inflammation, and Cancer. Cell, 140(6), 883899.

5. Smith H., \& Kang Y. (2013). The metastasis-promoting roles of tumor-associated immune cells. Journal Of Molecular Medicine, 91(4), 411-429. https://doi.org/10.1007/s00109-013-1021-5 PMID: 23515621

6. Gajewski T., Schreiber H., \& Fu Y. (2013). Innate and adaptive immune cells in the tumor microenvironment. Nature Immunology, 14(10), 1014-1022. https://doi.org/10.1038/ni.2703 PMID: 24048123

7. Pandya P., Murray M., Pollok K. and Renbarger J., 2016. The Immune System in Cancer Pathogenesis: Potential Therapeutic Approaches. Journal of Immunology Research, 2016, pp.1-13. https://doi.org/10. 1155/2016/4273943 PMID: 28116316

8. Büll C., Stoel M., den Brok M., \& Adema G. (2014). Sialic Acids Sweeten a Tumor's Life. Cancer Research, 74(12), 3199-3204. https://doi.org/10.1158/0008-5472.CAN-14-0728 PMID: 24830719

9. Rodrigues E. and Macauley M., 2018. Hypersialylation in Cancer: Modulation of Inflammation and Therapeutic Opportunities. Cancers, 10(6), p.207. https://doi.org/10.3390/cancers10060207 PMID: 29912148

10. Zhou X., Yang G., \& Guan F. (2020). Biological Functions and Analytical Strategies of Sialic Acids in Tumor. Cells, 9(2), 273. https://doi.org/10.3390/cells9020273 PMID: 31979120

11. Gopaul K., \& Crook M. (2006). Sialic acid: A novel marker of cardiovascular disease?. Clinical Biochemistry, 39(7), 667-681. https://doi.org/10.1016/j.clinbiochem.2006.02.010 PMID: 16624269

12. Klein A., Diaz S., Ferreira I., Lamblin G., Roussel P., \& Manzi A. (1997). New sialic acids from biological sources identified by a comprehensive and sensitive approach: liquid chromatography-electrospray ionization-mass spectrometry (LC-ESI-MS) of SIA quinoxalinones. Glycobiology, 7(3), 421-432. https:// doi.org/10.1093/glycob/7.3.421 PMID: 9147052 
13. Lacomba R., Salcedo J., Algria A., Jesus Lagarda M., Barbera R. and Matencio E., 2010. Determination of sialic acid and gangliosides in biological samples and dairy products: A review. Journal of Pharmaceutical and Biomedical Analysis, 51(2), pp.346-357. https://doi.org/10.1016/j.jpba.2009.04.023 PMID: 19481897

14. Rohrer J. (2000). Analyzing Sialic Acids Using High-Performance Anion-Exchange Chromatography with Pulsed Amperometric Detection. Analytical Biochemistry, 283(1), 3-9. https://doi.org/10.1006/ abio.2000.4643 PMID: 10929801

15. Lu X., Yasa I., Cutak B., Ray K., \& Bell D. (2015). Improving the Chromatographic Separation of DMBLabeled Sialic Acids for the Comparison of Biosimilars to Reference Materials. Reporter US, 33(2).

16. Hara S., Yamaguchi M., Takemori Y., Nakamura M., \& Ohkura Y. (1986). Highly sensitive determination of $\mathrm{N}$-acetyl- and $\mathrm{N}$-glycolylneuraminic acids in human serum and urine and rat serum by reversedphase liquid chromatography with fluorescence detection. Journal Of Chromatography B: Biomedical Sciences And Applications, 377, 111-119. https://doi.org/10.1016/s0378-4347(00)80766-5 PMID: 3711202

17. American Public Health Association. Compendium of methods for the microbiological examination of foods. 3rd ed. Washington, DC: American Public Health Association; 1992.

18. Miyagiwa M, Ichida $T$, Tokiwa $T$, Sato J, Sasaki $H$. A new human cholangiocellular carcinoma cell line (HuCCT-T1) producing carbohydrate antigen 19/9 in serum-free medium. In vitro Cellular \& Developmental Biology. 1989; 25(6):503-510.

19. Van den Bosch J., Oemardien L., Srebniak M., Piraud M., Huijmans J., Verheijen F., et al. (2011). Prenatal screening of sialic acid storage disease and confirmation in cultured fibroblasts by LC-MS/MS. Journal Of Inherited Metabolic Disease, 34(5), 1069-1073. https://doi.org/10.1007/s10545-011-9351-3 PMID: 21617927

20. Gabriele C., Cantiello F., Nicastri A., Crocerossa F., Russo G., \& Cicione A. et al. (2018). High-throughput detection of low abundance sialylated glycoproteins in human serum by TiO2 enrichment and targeted LC-MS/MS analysis: application to a prostate cancer sample set. Analytical And Bioanalytical Chemistry, 411(3), 755-763. https://doi.org/10.1007/s00216-018-1497-5 PMID: 30483857 